\title{
The Effect of Coronavirus 2019 Disease Control Measures on the Incidence of Respiratory Infectious Disease and Air Pollutant Concentrations in Yangtze River Delta Region, China
}

\section{Lan Wang ( $\nabla$ wanglan@zju.edu.cn )}

Zhejiang University School of Medicine First Affiliated Hospital https://orcid.org/0000-0003-1369-0584

\section{Kehan Wang}

Renmin University of China School of Statistics

Hui Zhong

Sun Yat-sen University School of Data and Computer Science

$\mathrm{Na}$ Zhao

Chinese Academy of Sciences

\section{Yunmei Yang}

Zhejiang University School of Medicine First Affiliated Hospital

\section{Yiran He}

Renmin University of China School of Statistics

\section{Shelan Liu}

Zhejiang Provincial CDC: Zhejiang Provincial Center for Disease Control and Prevention https://orcid.org/0000-0003-2053-0941

\section{Wangli Xu}

Renmin University of China School of Statistics

\section{Research Article}

Keywords: respiratory infectious disease incidence, air pollutant concentrations, China, influenza, air quality, coronavirus disease 2019

Posted Date: June 3rd, 2021

DOl: https://doi.org/10.21203/rs.3.rs-525693/v1

License: (c) (i) This work is licensed under a Creative Commons Attribution 4.0 International License. Read Full License 
Version of Record: A version of this preprint was published at International Journal of Environmental Research and Public Health on January 24th, 2022. See the published version at https://doi.org/10.3390/ijerph19031286. 


\section{Abstract}

To investigate the changes of the respiratory infectious diseases (RID) and air quality during the COVID19 outbreak over Yangtze River Delta Region, China. We investigate the impact of COVID-19 control measures on changes of RID and air quality by constructing two proportional test and fitting ARIMA and piecewise regression models. A total of 81,345 and $1,048,511$ cases of RID were identified in Shanghai and Zhejiang Province, respectively. The incidence of seven RID and influenza decreased by $37.80 \%$ and $49.57 \%$ in 2020 in Shanghai and decreased by $20.39 \%$ and $43.40 \%$ in Zhejiang Province, respectively. The monthly concentrations of overall air pollutants decreased by $12.7 \%$ and $12.85 \%$ in 2020 Shanghai and Zhejiang compared to the 2017-2019 period; the most rapid decrease was observed in $\mathrm{SO}_{2}$ concentrations (32.39\% and 33.37\% in Shanghai Province and Zhejiang Province, respectively). A moderate correlation was seen between influenza incidence and monthly $\mathrm{SO}_{2}$ concentrations in Shanghai $(r=0.59)$. A $10 \mu \mathrm{g} / \mathrm{m}^{3}$ decrease of $\mathrm{SO}_{2}$ was significantly associated with the reduction of influenza incidence $(2907.76$ per 100,000$)$. This study provided the additional evidences that the measures taken for COVID-19 were effective in improving the air quality and reducing spread of other common respiratory diseases, but direct causality is not established.

\section{Introduction}

Coronavirus disease 2019 (COVID-19) was first identified in Wuhan, China, in December 2019, and, since then, the number of COVID-19 cases has rapidly surged worldwide [1]. It was declared a pandemic by the World Health Organization (WHO) on 11 March 2020 [2]. By 7 March 2020, 116,166,652 confirmed cases and 2,582,528 deaths had been reported in at least 200 countries, areas or territories [3].

In China, the emergence of a Severe Acute Respiratory Syndrome Coronavirus-2 (SARS-CoV-2) was first confirmed in Wuhan city, SARSCoV-2 spread rapidly to many other cities of Hubei province and outside of Hubei provinces rapidly during January 2020[4-5]. In response the threat, the Chinese government implemented numerous strict measures to control the SARS-CoV-2 transmission during the initial emergency response to COVID-2019 outbreak stage between January and March 2020 [6]. China controlled its initial COVID-19 epidemic in March 2020 and since April 29 of 2020, China have entered the routine control stages of suppression COVID-19 [7]. Although dozens of small COVID-19 outbreaks occurred in Shijiazhuang of Hebei Province, Beijing, Jilin Province, and the Xinjiang Uygur Autonomous Region since June of 2020 [8-9], they were controlled by unremitting containment and suppression [10]. Nonpharmaceutical interventions (NPIs) have included lockdowns, the closure of schools, delayed returns to school, travel restrictions, stay-home orders, event bans, quarantines, curfews, and mask mandates, etc. NPIs have also decreased the incidence of common respiratory infectious diseases(RID), including influenza, respiratory syncytial virus and adenovirus in "New Zealand, USA, and Japan, etc. [11-15]. However, the effect of the measures taken to contain COVID-19 on the rate of respiratory infectious disease (other than COVID-19) in China remains unclear. 
Of the various areas affected by COVID-19 in China, the Yangtze River Delta region (YRD) is one of the top five regions, with 1,835 and 1,322 confirmed cases having been respectively reported in Shanghai and Zhejiang Province as of 16 March 2021 by Local Health Commissions. This YRD is one of the most densely populated regions on earth and belongs to developed areas of China, with over 150 million registered residents, and it is characterized by highly sensitive disease surveillance, reporting, and detection capabilities regarding infectious disease. However, a better understanding is required of the effect of the COVID-19 control measures, implemented in 2020, on the incidence of respiratory infections in Shanghai and Zhejiang Province of China.

In 2019, the WHO listed 10 environmental threats to global health; of these, air pollution was considered to be the greatest [16]. Previous studies have demonstrated a positive association between exposure to air pollution and the rate of respiratory infectious disease [16-17]. For example, recent studies from China reported that short-term exposure to $\mathrm{PM}_{2.5}, \mathrm{PM}_{10}, \mathrm{CO}, \mathrm{NO}_{2}$ and $\mathrm{O}_{3}$ concentrations was significantly associated with confirmed COVID-19 cases [18]. Thus, a decision was made in the current study to assess the association between air pollutant concentration and the incidence of respiratory infectious disease during the COVID-19 pandemic in 2020. A comparison was performed of the incidence of eight common respiratory infectious diseases (i.e. epidemic parotitis, influenza, measles, pulmonary tuberculosis, rubella, scarlet fever, and pertussis) and six air pollutants (i.e. $\mathrm{PM}_{2.5}, \mathrm{PM}_{10}, \mathrm{NO}_{2}, \mathrm{SO}_{2}, \mathrm{CO}$ and $\mathrm{O}_{3}$ ) in Shanghai and Zhejiang Province in 2020 and in the 2017-2019 period. In addition, an attempt was made to identify potential environmental risks associated with this change of RID in Shanghai and Zhejiang Province of China.

\section{Materials And Methods}

\section{Ethics statement}

This study was conducted according to the principles and guidelines of the Declaration of Helsinki, and was approved by the Research Ethics Committee of the Zhejiang Provincial Center for Disease Control and Prevention(No.2020-24). All initial information identifying patients was anonymized in this study.

\section{Data collection (eight RID)}

Two data sources, Shanghai Municipal Health Commission and the Health Commission of Zhejiang Province of China, were used to obtain information on the incidence of the aforementioned eight common RID. The data included details (i.e. number of cases, incidence and patient data stratified by onset date [month and year] and area) of probable, clinically diagnosed and confirmed cases of respiratory infectious disease. The population data were acquired from the National Bureau of Statistics of the People's Republic of China, updated at the end of each year.

\section{Data collection (air pollutants)}


The mean monthly and monthly data on the concentrations of the aforementioned six air pollutants in Shanghai and Zhejiang Province were obtained from an air pollution database in the east of China managed by Sun Yat-sen University. The data were obtained from 19 and 56 air quality monitoring stations in Shanghai and Zhejiang Province of China, respectively (Supplementary Fig. 1).

\section{Case Definitions}

The diagnostic criteria of all eight RID has been issued by the National Health Commission of the People's Republic of China, see Supplementary table1(1 7). However, the case definition of seasonal influenza was changed since 2019. The confirmed cases for seasonal influenza were defined as: the clinical presentation is that of any of a number of acute febrile respiratory diseases, i.e., fever, cough, coryza, difficulty breathing or with a history of contact with a confirmed or suspected case and a laboratory test positive for influenza virus, including influenza antigen, PCR, viral isolation or a four-fold or greater increase in serum antibodies specific for this virus isolated in paired sera.

\section{Statistical analysis}

The monthly and annual incidence of respiratory infectious disease (per 100,000) was defined as the number of monthly and annual cases of respiratory infectious diseases divided by population size. To visually demonstrate the impact of COVID-19 on the incidence of respiratory infectious disease, the data were categorized according to different stages (i.e. the 2017-2019 period [pre-COVID-19] and 2020 [post COVID-19]). Comparisons of the average annual incidence of RID and air pollutant concentrations in aforementioned two stages were conducted using a two proportional test statistics with asymptotical normal distribution. We used the seasonal ARIMA model (Box and Jenkins,1976) to predict the incidence of respiratory diseases and the concentration of air pollutants during 2020 COVID-19 outbreak, and two proportional tests were constructed to check whether the real incidence is same as the predicted incidence of RID during 2020. The widely-used Pearson correlation coefficient was to calculate the association between the incidence of respiratory diseases and air pollutants for Shanghai and Zhejiang. A two-ratio test for checking whether the incidence is equal during the emergency stage and in a routine period. The piecewise regression model in Toms and Lesperance (2003) is to identify of changes of incidence data. A p value of $<0.05$ was considered to be statistically significant. All analysis in this study were conducted using R statistical software. The seasonal ARIMA model was constructed by using the function "Auto. arima" in the forecast package, and the piecewise linear regression model was constructed by using the "piecewise.linear" in the Sizer package.

\section{Results}

\section{Descriptive analysis of the difference in the incidence of RID between the 2017-2019 period and 2020}

Between 2017 and 2020, 81,345 and 1,048,511 cases of eight different types of RID were reported in Shanghai and Zhejiang Province, respectively. The average annual incidence of RID (per 100,000 people) 
was 140.64 cases and 525.01 cases in Shanghai and Zhejiang Province, respectively. The incidence (per 100,000 ) for seven of the eight RID (excepting influenza) decreased by $37.80 \%$ (95\% confidence interval [CI]: 35.15-40.45) from 61.26 in the 2017-2019 period to 38.10 in $2020(p=<0.001)$ in Shanghai

(Figs. 1,2 and Supplementary Table 2), and decreased by $20.39 \%$ (95\% Cl: 19.17-21.61) from 93.02 in the 2017-2019 period to 74.05 in $2020(p=<0.001)$ in Zhejiang Province (Figs. 1,2, Supplementary Table 3). The incidence of influenza decreased by $49.57 \%$ (95\% Cl: $48.10-51.04)$ and $43.40 \%$ (95\% Cl: $43.05-$ 43.76) in Shanghai and Zhejiang Province, respectively, between 2019 and $2020(p=<0.001)$ (Supplementary Tables 2 and 3, Fig. 3). Generally, the average annual incidence of overall RID was considerably higher in Zhejiang Province than that in Shanghai for both periods (Supplementary Table 4).

Descriptive analysis of the difference in the incidence of overall RID during the emergency and routine responses toCOVID-19 in 2020

The monthly incidence of overall RID was considerably higher in Zhejiang Province than in Shanghai for both periods ( $p=<0.050$ ) (Fig. 4). The 2020 period under evaluation was divided into an emergency response (to COVID-19) stage (January to April 2020) and a routine response (to COVID-19) stage (May to December 2020). During the emergency response stage, the overall incidence of seven RID decreased significantly, by $37.76 \%$ in Shanghai (95\% Cl: 28.07-47.46) $(\mathrm{p}=<0.001)$ (Fig. 5 and Supplementary Table 5) and by $22.76 \%$ in Zhejiang (95\% Cl: 18.44-27.07) $(p=<0.001)$ (Fig. 6 and Supplementary Table 6). During the routine response stage, for seven of the eight RID (excepting influenza), the overall incidence of RID decreased by $37.81 \%$ (95\% Cl: $28.85-46.78)$ and $19.30 \%(95 \% \mathrm{Cl}: 15.13-23.47)$ in Shanghai and Zhejiang Province, respectively ( $p=<0.001)$ (Figs. 5 and 6, Supplementary Tables 5 and 6).

The influenza activity decreased significantly in throughout 2020, Shanghai, particularly in the routine stages (95.65\% reduction, $95 \% \mathrm{Cl}$ : 90.62 to 100.68$)$ (Supplementary Table 5). However, the influenza mildly increased in Zhejiang Province (16.21\% escalation, $95 \% \mathrm{Cl}: 15.00$ to 17.41$)$ in the emergency stages of 2020 , suddenly decreased by $97.66 \%$ reduction, $95 \% \mathrm{Cl}$ : 96.54 to 98.78 ) in the routine stage (Supplementary Table 6).

\section{Descriptive analysis of the difference in overall actual and predicted rates of respiratory infectious} disease in 2020

A seasonal ARIMA model was used to predict the incidence of RID and to compare the difference in actual and predicted incidence. In Shanghai, actual overall eight RID incidence was $52.60 \%$ (95\% Cl: 51.41 to $53.78, p<0.001$ ) lower than the predicted rate ( 131.63 vs. 277.69 per 100,000 population, Fig. 7 and Supplementary Table 7). Similarly, in Zhejiang Province, true incidence was considerably lower (by $24.06 \%)$ than predicted incidence (95\% Cl: $23.66-24.46,611.66$ versus 805.49 per 100,000 population) $(p=<0.001)$ (Fig. 7 and Supplementary Table 8).

\section{Descriptive analysis of the difference in air pollutant concentrations between the 2017-2019 period and 2020}


The monthly concentrations of overall six air pollutants (i.e. $\mathrm{PM}_{2.5}, \mathrm{PM}_{10}, \mathrm{NO}_{2}, \mathrm{SO}_{2}, \mathrm{CO}$ and $\mathrm{O}_{3}$ ) decreased by $12.7 \%$ (95\% Cl: $4.82-20.49, \mathrm{p}=0.003)$ and $12.85 \%(95 \% \mathrm{Cl}: 3.80-21.89, \mathrm{p}=0.008)$ in Shanghai and Zhejiang in 2020 compared to the 2017-2019 period (Supplementary Table 9). The most rapid decrease pertained to $\mathrm{SO}_{2}$ concentrations, which decreased by 32.39\% in Shanghai (95\% Cl: 20.61-44.17) and by $33.37 \%$ in Zhejiang Province (95\% Cl: 21.21-45.53) ( $p=<0.001)$ (Supplementary Table 9). The next largest decrease was observed in $\mathrm{PM}_{2.5}$ concentrations, which dropped by $26.30 \%$ in Zhejiang Province (95\% Cl: 8.97-43.62) ( $p=>0.050)$; followed by $\mathrm{PM}_{10}$ concentrations $(22.39 \%)$ in Shanghai $(95 \% \mathrm{Cl}$ : 10.23-34.54) $(p=<0.001)$; $\mathrm{PM}_{10}$ concentrations (19.82\%) in Zhejiang Province (95\% Cl: $\left.4.21-35.43\right)(p=$ $<0.050)$ and $\mathrm{PM}_{2.5}$ concentrations (12.80\%) in Shanghai (95\% Cl: 7.24-32.84) $(p=>0.050)$ (Fig. 8 and Supplementary Table 9).

\section{An analysis of the relationship between the incidences of RID and air pollutant concentrations}

The monthly concentrations of six air pollutants except $\mathrm{O}_{3}$ were not found to correlate significantly with the overall incidence of seven RID $(p=>0.050)$ in Shanghai and Zhejiang Province. A moderate positive correlation was identified between the incidence of influenza and monthly $\mathrm{NO}_{2}$ concentrations $(r=0.65)$, $\mathrm{SO}_{2}$ concentrations $(r=0.59), \mathrm{PM}_{10}$ concentrations $(r=0.45)$, and $\mathrm{PM}_{2.5}$ concentrations $(r=0.43)$ in Shanghai; CO concentrations ( $r=0.66), \mathrm{PM}_{2.5}$ concentrations ( $\left.r=0.52\right)$, and $\mathrm{NO}_{2}$ concentrations $(r=0.34)$ in Zhejiang Province when evaluated using Poisson regression $(p=<0.050)$ (Fig. 9).

The negative association between $\mathrm{O}_{3}$ and influenza incidence was both found in Shanghai $(r=-0.64)$ and Zhejiang Province $(r=-0.54)$.

We used the piecewise linear regression models to determine the impact of air pollutant concentration on the incidence of influenza. The results showed that $\mathrm{SO}_{2}$ and $\mathrm{PM}_{2.5}$ concentrations were positively associated with influenza incidence in Shanghai. The corresponding change points for $\mathrm{SO}_{2}$ and $\mathrm{PM}_{2.5}$ concentrations were $0.24 \mu \mathrm{g} / \mathrm{m}^{3}$ and $0.05 \mu \mathrm{g} / \mathrm{m}^{3}$, respectively (Fig. 10a). That is, when the concentration of $\mathrm{SO}_{2}$ was greater than $0.24 \mu \mathrm{g} / \mathrm{m}^{3}$ or the concentration of $\mathrm{PM}_{2.5}$ was greater than $0.05 \mu \mathrm{g} / \mathrm{m}^{3}$, the incidence of influenza increased with the $\mathrm{SO}_{2}$ and $\mathrm{PM}_{2.5}$ concentrations increased. Similarity, $\mathrm{PM}_{10}, \mathrm{NO}_{2}$ and $\mathrm{CO}$ concentrations were shown to positively correlate with influenza incidence. However, $\mathrm{O}_{3}$ concentrations were observed to negatively correlate influenza incidence (Fig. 10b). In Zhejiang Province, $\mathrm{PM}_{2.5}$ and $\mathrm{CO}$ concentrations had a positive association with influenza incidence; conversely, $\mathrm{O}_{3}$ concentrations negatively correlated with influenza incidence (Fig. 10c).

\section{Discussion}

Using representative data from the Yangtze River Delta Region, China, the current study identified a marked decline in the overall annual incidence of eight respiratory infectious diseases in 2020, compared 
to the previous three years. The overall incidence of respiratory infectious disease in 2020 was lower than that predicted in both regions in 2020. A similar decrease was demonstrated in the concentrations of six air pollutants in 2020; of these, $\mathrm{SO}_{2}, \mathrm{PM}_{2.5}$ and $\mathrm{PM}_{10}$ were significantly associated with a decrease in influenza incidence.

Since Shanghai and Zhejiang Province are geographically proximal to Hubei Province, a large number of the population returned from Hubei Province before Wuhan went into lockdown on 23 January 2020. Both areas were the first to be impacted by COVID-19 [5]. Zhejiang Province and Shanghai reported the first imported cases of COVID-19 (i.e. from Hubei Province) on 20 January 2020 and 23 January 2020, respectively [19]. Thereafter, COVID-19 rapidly spread, over the next two months, to 11 cities in Zhejiang Province and to 16 Shanghai districts. In response to this novel threat, on 23 January 2020, the governor initiated a top levl emergency response to COVID-19 for implementation in Zhejiang Province and Shanghai. The application of strict precautionary measures, such as lockdowns, home stays, the closure of schools and the suspension of large-scale events, disrupted the transmission of COVID-19, which simultaneously resulted in a decrease in the incidence of other respiratory infectious diseases, including influenza. In this regard, the findings of the current study support those of studies conducted outside China $[12-14,20]$. Several explanations have been posited for the decrease in the incidence of respiratory infectious diseases. Firstly, these diseases have a similar mode of transmission to COVID-19 (i.e., via respiratory transmission or contact) [12-13]; therefore, it may be assumed that interventions to prevent COVID-19 have reduced the spread of respiratory infectious disease. Secondly, difficulty accessing hospital services during COVID-19 owing to strict quarantine measures, together with fears of contracting COVID-19 at a hospital, have inhibited opportunities for disease transmission [11]. Lastly, people's hygiene habits have improved considerably as it is mandatory to wear masks, regularly wash hands and implement proper ventilation. Generally, it is feasible that the lockdown, in conjunction with healthseeking behavioural changes and improved personal hygiene, has reduced the risk of the transmission of respiratory infectious disease pathogens $[10-14,20]$.

In the current study, the rate of influenza slightly increased during the emergency response (to COVID-19) stage in Zhejiang Province, which could have been owing to awareness of similarities in respiratory infectious disease and COVID-19 symptoms, together with enhanced surveillance, testing and diagnostic strategies for influenza-like illnesses in early 2020. However, the incidence of influenza remained significantly low during the routine response (to COVID-19) stage in both regions. This finding could be attributed to the efficacy of SARS-CoV-2 prevention strategies.

COVID-19 prompted a period of nationwide public lockdown, which provided an invaluable opportunity for an evaluation of the correlation between air pollutant concentrations and RID. In the current study, the monthly concentrations of six air pollutants were found to decrease significantly in 2020 , compared to the previous three years, and the levels were much lower than those stipulated in the Chinese guidelines [16].The most significant decrease was seen in $\mathrm{SO}_{2}$ concentrations in both regions. In 2020, this reduction can be attributed to by the reduction of the primary air pollutant emissions, for example, almost all medium and small industries except power plants and large-scale enterprises were closed [21]. In 
addition, officially, the YRD cities started its full lockdown on January 23rd -25th and remained in place until the end of April, these policies have led to reduced human activities, which caused improvement of air quality as a side-product. Similar findings were reported elsewhere in this regard [21].

It was curious to determine if low air pollutant concentrations were associated with the decrease in the incidence of RID. As with previous findings, it was established that the decrease in short-term exposure by people to air pollutants inhibited the spread of RID in the Yangtze River Delta Region, China. Specially, the $\mathrm{SO}_{2}$ and $\mathrm{NO}_{2}$ concentration in Shanghai and $\mathrm{PM}_{2.5}$ and $\mathrm{CO}$ in Zhejiang Province had significant effects on the incidence of influenza.

The reasons were not clear, which might be driven by the difference of primary emissions, population dentistry, and energy and industrial strategy, etc. Firstly, a recent epidemiological study concluded that decreased short-term exposure to particulate matter was associated with a decline in the use of healthcare services for acute lower respiratory infections [22]. Secondly, exposure to urban airborne particulate matter has been demonstrated to alter the macrophage-mediated inflammatory response to respiratory viral infection $[18,22]$. Thirdly, exposure to $\mathrm{PM}_{10}$ and $\mathrm{PM}_{2.5}$ concentrations could significantly enhance RNA virus infections, such as $\mathrm{H} 1 \mathrm{~N} 1$ and H5N1, in A459 human lung epithelial cells by increasing viral replications $[16,23]$. Fourthly, air pollutants affect the lower respiratory tract protease-antiprotease balance and microflora, which are associated with respiratory infections [18].

To the best of our knowledge, this is the first study to have evaluated differences in the incidence of respiratory infectious disease and air pollutant concentrations in the Yangtze River Delta Region, China, between the period, 2017-2019 (pre-COVID-19), and 2020 (post COVID-19). However, the study had several limitations. Firstly, the evaluation was limited to air pollutants, and it is possible that other meteorological factors might have influenced the transmission and pathogenesis of respiratory infections. Secondly, this study might have the

reporting biases because of health-care seeking behavior and laboratory capacity.Thirdly, this is an ecological study, and we can find the decline of RID and six air pollutants. However, current evidence cannot justify any causal relationship between air pollution and RID downtrends during 2020.

\section{Conclusion}

The current study indicated that the incidence of eight RID and the concentration of six air pollutants in Shanghai and Zhejiang Province decreased significantly in 2020 compared to the previous three years. The most significant reduction pertained to $\mathrm{SO}_{2}$ concentrations in both areas. During the most stringent emergency response period, the overall RID has been reduced by $37.76 \%$ and $22.76 \%$ in Shanghai and Zhejiang Province respectively. The influenza reduction was positively related with the $\mathrm{NO}_{2}$ and $\mathrm{SO}_{2}$ in Shanghai but associated with the $\mathrm{CO}$ and $\mathrm{PM}_{2.5}$ in Zhejiang Province. This study provided the additional evidences that the measures taken for COVID-19 were effective in improving the air quality greatly and decreased the other RID. In future studies, the accurate mechanisms should be explored further that 
utilise a large-sample design; more stringent regional jointcontrol within YRD should be pushed forward to achive a better air quality and infectious disease control.

\section{Declarations}

\section{Funding}

This work was supported by the Beijing Natural Science Foundation (Z20001), the Research Funds for the Major Innovation Platform of Public Health \& Disease Control and Prevention, Renmin University of China and National Natural Science Foundation of China (11971478) and supported by the National Natural Science Foundation of China (No. 31901120). This research was supported by Zhejiang Provincial Natural Science Foundation of China under Grant No. GF21H260012खSupported by the Non-profit Central Research Institute Fund of Chinese Academy of Medical Sciences Grant No:2020-PT330-003; Health Commission of Zhejiang Province, China under Grant No.WKJ-ZJ-2106

\section{Conflict of interest}

All authors have no conflict of interest to declare.

\section{Acknowledgements}

We are grateful to Stu. King Wun Lau from Shanghai High School International Division, Shanghai, China for his assistance in collecting raw data and inputting the data.

\section{References}

1. Zhu N, Zhang D, Wang W, Li X, Yang B, Song J, Zhao X, Huang B, Shi W, Lu R, Niu P, Zhan F, Ma X, Wang D, Xu W, Wu G, Gao GF, Tan W; China Novel Coronavirus Investigating and Research Team(2020). A novel coronavirus from patients with pneumonia in China, 2019. N Engl J Med 382(8):727-733. https://doi.org/10.1056/NEJMoa2001017

\section{WHO. Characterizes COVID-19 outbreak as pandemic-11 March 2020. Available at}

\section{3. https://}

4. WHO. WHO Director-General's opening remarks at the media briefing on COVID-19-12 March 2021. Available at: https://www.who.int/director-general/speeches/detail/who-director-general-s-openingremarks-at-the-media-briefing-on-covid-19-12-march-2021

5. Li Q, Guan X, Wu P, Wang X, Zhou L, Tong Y, Ren R, Leung KSM, Lau EHY, Wong JY, Xing X, Xiang N, Wu Y, Li C, Chen Q, Li D, Liu T, Zhao J, Liu M, Tu W, Chen C, Jin L, Yang R, Wang Q, Zhou S, Wang R, Liu H, Luo Y, Liu Y, Shao G, Li H, Tao Z, Yang Y, Deng Z, Liu B, Ma Z, Zhang Y, Shi G, Lam TTY, Wu JT, Gao GF, Cowling BJ, Yang B, Leung GM, Feng (2020)Z. Early transmission dynamics in Wuhan, China, of novel coronavirus-infected pneumonia. N Engl J Med 382(13):1199-1207. https://doi.org/10.1056/NEJMoa2001316 
6. Liu J, Zhang L, Yan Y, Zhou Y, Yin P, Qi J, Wang L, Pan J, You J, Yang J, Zhao Z, Wang W, Liu Y, Lin L, Wu J, Li X, Chen Z, Zhou M(2021) Excess mortality in Wuhan city and other parts of China during the three months of the COVID-19 outbreak: findings from nationwide mortality registries. BMJ 372 : n415. https://doi.org/10.1136/bmj.n415

7. Li Z, Chen Q, Feng L, Rodewald L, Xia Y, Yu H, Zhang R, An Z, Yin W, Chen W, Qin Y, Peng Z, Zhang T, Ni D, Cui J, Wang Q, Yang X, Zhang M, Ren X, Wu D, Sun X, Li Y, Zhou L, Qi X, Song T, Gao GF, Feng Z; China CDC COVID-19 Emergency Response Strategy Team(2020) Active case finding with case management: the key to tackling the COVID-19 pandemic. Lancet 396(10243):63-70. https://doi.org/10.1016/S0140-6736(20)31278-2

8. Ren R, Zhang Y, Li Q, McGoogan JM, Feng Z, Gao GF, Wu Z (2021) Asymptomatic SARS-CoV-2 infections among persons entering China from April 16 to October 12, 2020. JAMA 325(5):489-492. https://doi.org/10.1001/jama.2020.23942

9. Attanayake A, Perera SSN, Jayasinghe S(2020) Phenomenological modelling of COVID-19 epidemics in Sri Lanka, Italy, the United States, and Hebei Province of China. Comput Math Methods Med 2020: 6397063. https://doi.org/10.1155/2020

10. Wang XY, Zhang YQ, Cai LW (2021) Spatiotemporal characteristics of the COVID-19 resurgence in the metropolitan wholesale market of Beijing, China. J Travel Med 28(2):taab008.

https://doi.org/10.1093/jtm/taab008. 0

11. Gao GF (2021) COVID-19: a year long and beyond? China CDC Weekly 3(8):2 0

12. Lee HH, Lin SH(2020) Effects of COVID-19 prevention measures on other common infections, Taiwan. Emerg Infect Dis 26(10):2509-2511. https://doi.org/10.3201 /eid2610.203193

13. Soo RJJ, Chiew CJ, Ma S, Pung R, Lee V (2020) Decreased influenza incidence under COVID-19 control measures, Singapore. Emerg Infect Dis 26(8):1933-1935. https://doi.org/10.3201/eid2608.201229

14. Trenholme A, Webb R, Lawrence S, Arrol S, Taylor S, Ameratunga S, Byrnes CA(2021) COVID-19 and infant hospitalizations for seasonal respiratory virus infections, New Zealand, 2020. Emerg Infect Disc27(2):641-643. https://doi.org/10.3201/eid2702.204041

15. Wong NS, Leung CC, Lee SS(2020) Abrupt subsidence of seasonal influenza after COVID-19 outbreak, Hong Kong, China. Emerg Infect Dis 26(11):2753-2755. https://doi.org/10.3201/eid2611.200861

16. Wormser GP(2020) COVID-19 versus seasonal influenza 2019-2020: USA. Wiener klinische Wochenschrift 132(13-14):387-389. https://doi.org/10.1007/s00508-020-01685-y

17. Liu Y, Ding H, Chang ST, Lu R, Zhong H, Zhao N, Lin TH, Bao Y, Yap L, Xu W, Wang M, Li Y, Qin S, Zhao Y, Geng X, Wang S, Chen E, Yu Z, Chan TC, Liu S(2020) Exposure to air pollution and scarlet fever resurgence in China: a six-year surveillance study. Nat Commun 11(1):4229. https://doi.org/10.1038/s41467-020-17987-8

18. GBD 2016 Lower Respiratory Infections Collaborators(2018) Estimates of the global, regional, and national morbidity, mortality, and aetiologies of lower respiratory infections in 195 countries, 1990- 
2016: a systematic analysis for the Global Burden of Disease Study 2016. Lancet Infect Dis 18(11):1191-1210. https://doi.org/10.1016/S1473-3099(18)30310-4.

19. Adhikari A, Yin J(2020) Short-term effects of ambient ozone, PM2.5, and meteorological factors on COVID-19 confirmed cases and deaths in Queens, New York. Int J Environ Res Public Health 17(11):4047. https://doi.org/10.3390/ijerph17114047.

20. Cai JH, Wang XS, Ge YL, Xia AM, Chang HL, Tian H, Zhu YX, Wang QR, Zeng JS(2020) First case of 2019 novel coronavirus infection in children in Shanghai. Chinese Journal Pediatrics 58(2):86-87. https://doi.org/10.3760/cma.j.issn.0578-1310.2020.02.002

21. Sakamoto H, Ishikane M, Ueda $P(2020)$ Seasonal influenza activity during the SARS-CoV-2 outbreak in Japan. JAMA 323(19):1969-1971. https://doi.org/10.1001/jama.2020.6173

22. Yuan Q, Qi B, Hu D, Wang J, Zhang J, Yang H, Zhang S, Liu L, Xu L, Li W(2021) Spatiotemporal variations and reduction of air pollutants during the COVID-19 pandemic in a megacity of Yangtze River Delta in China. Sci Total Environ 751:141820. https://doi.org/10.1016/j.scitotenv.2020.141820

23. Becker S, Soukup JM(1999) Exposure to urban air particulates alters the macrophage-mediated inflammatory response to respiratory viral infection. J Toxicol Environ Health A 57(7):445-457. https://doi.org/10.1080/009841099157539

24. Ng YC, Chung WC, Kang HR, Cho HJ, Park EB, Kang SJ, Song MJ(2018) A DNA-sensing-independent role of a nuclear RNA helicase, DHX9, in stimulation of NF-KB-mediated innate immunity against DNA virus infection. Nucleic Acids Res 46(17):9011-9026. https://doi.org/10.1093/nar

\section{Figures}




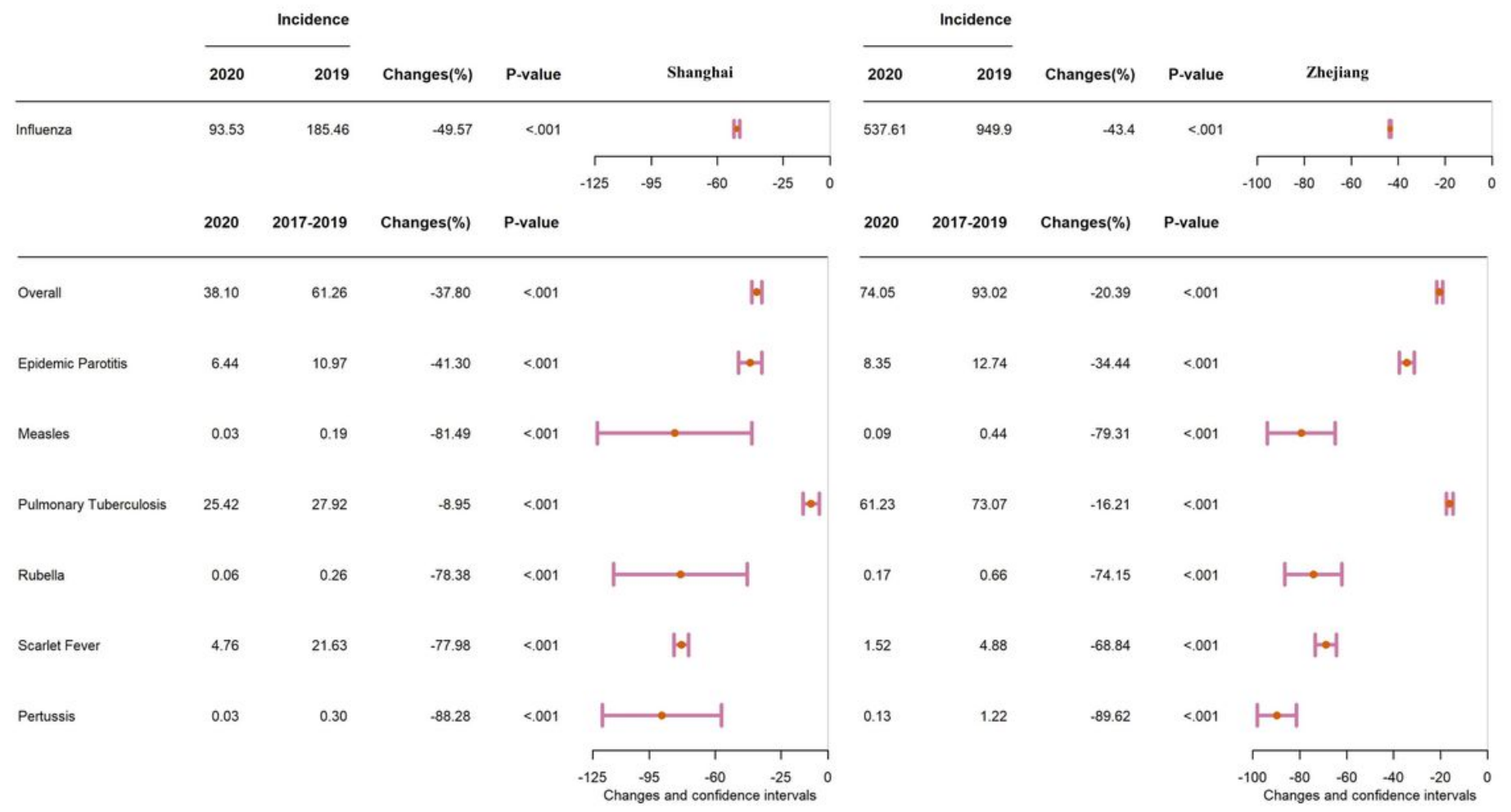

\section{Figure 1}

Differences in the average annual incidence of eight respiratory infectious diseases in Shanghai and Zhejiang Province Notes: The pink lines reflect differences in the $95 \%$ confidence interval values. The pink dot indicates the $50 \%$ median point. Changes $=(x 2-x 1) / x 1 \times 100 \%, x 1$ : average annual incidence of respiratory infectious disease in 2017-2019, x2: average yearly incidence in 2020 . The p-values were computed using two proportional tests . 
Overall Zhejiang

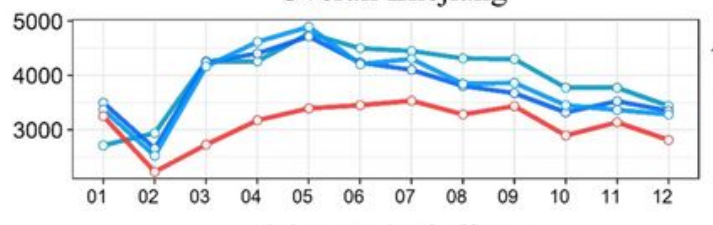

COVID19 Zhejiang

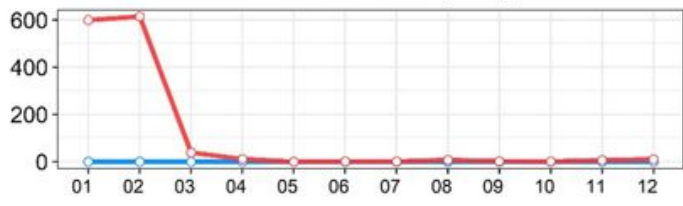

Epidemic Parotitis Zhejiang

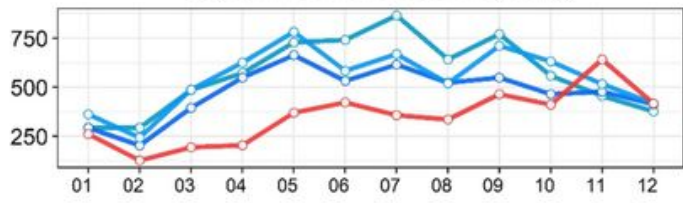

Measles Zhejiang
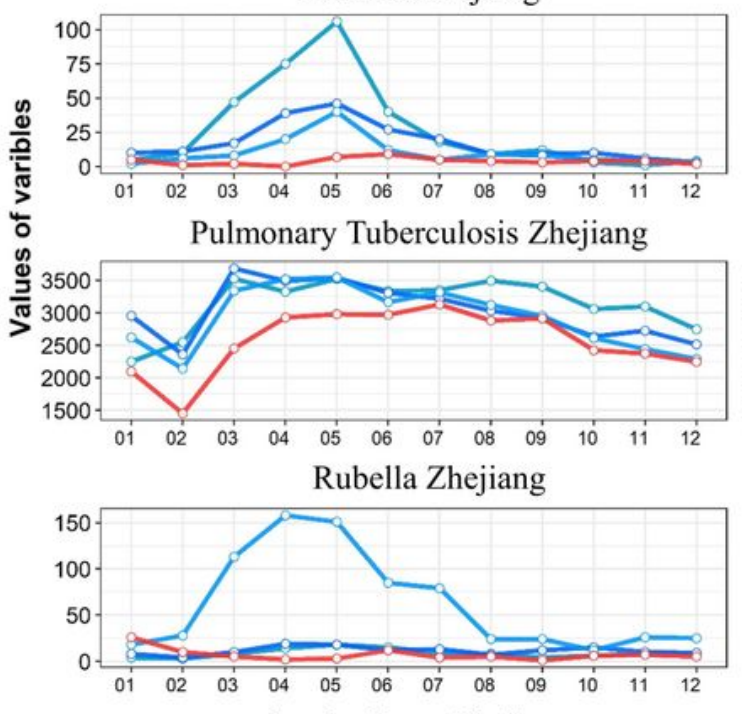

Scarlet Fever Zhejiang
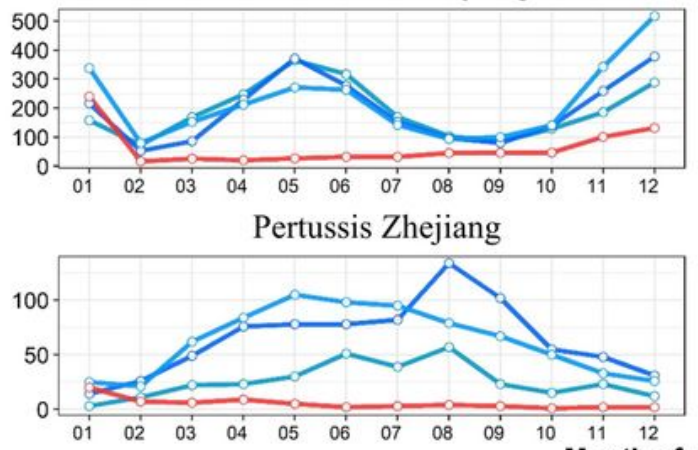

Overall Shanghai

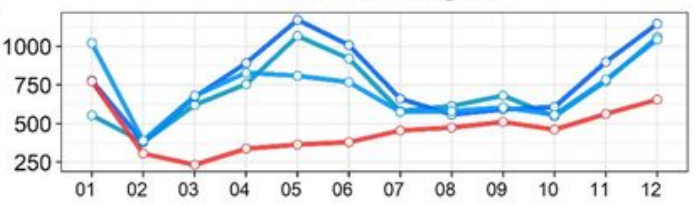

COVID19 Shanghai

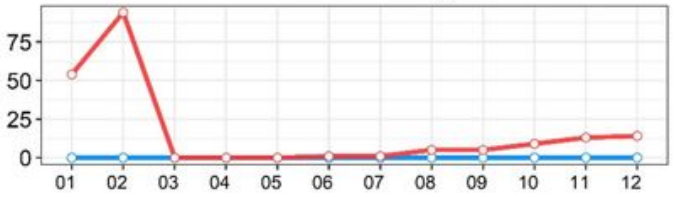

Epidemic Parotitis Shanghai

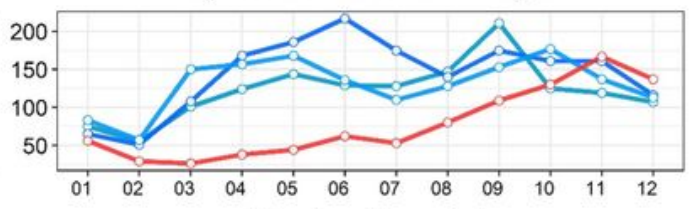

Measles Shanghai

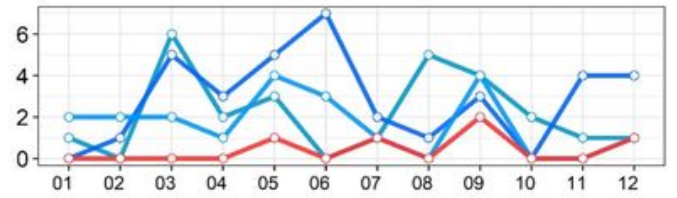

$-2017$

- 2018

2019

$-2020$
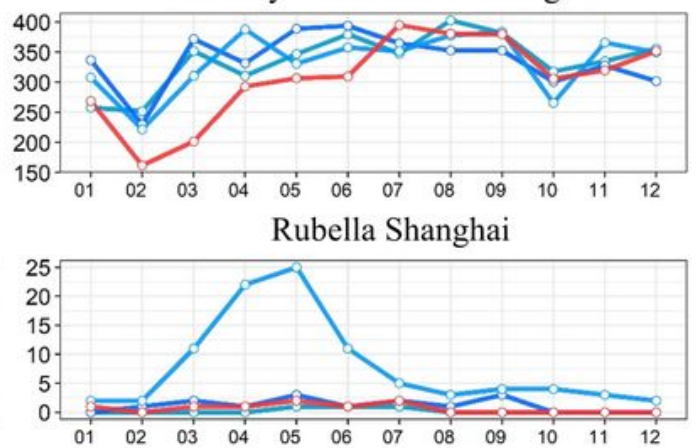

Scarlet Fever Shanghai
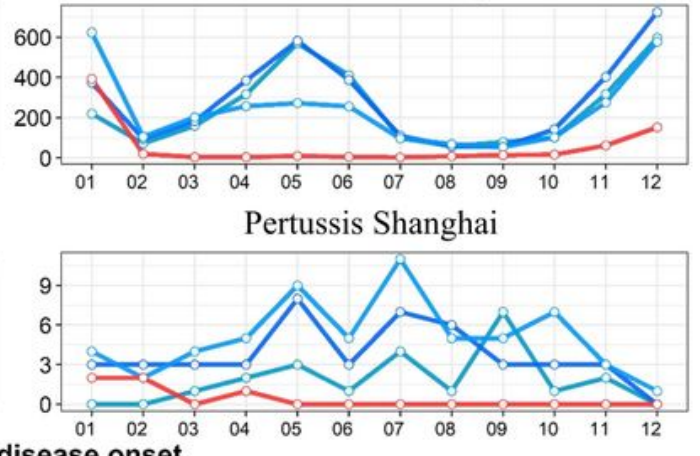

\section{Figure 2}

Differences in the monthly cases of seven respiratory infectious diseases in Zhejiang and Shanghai between the 2017-2019 period and 2020 Notes: The horizontal and vertical axes depict the onset months and number of monthly cases, respectively. 

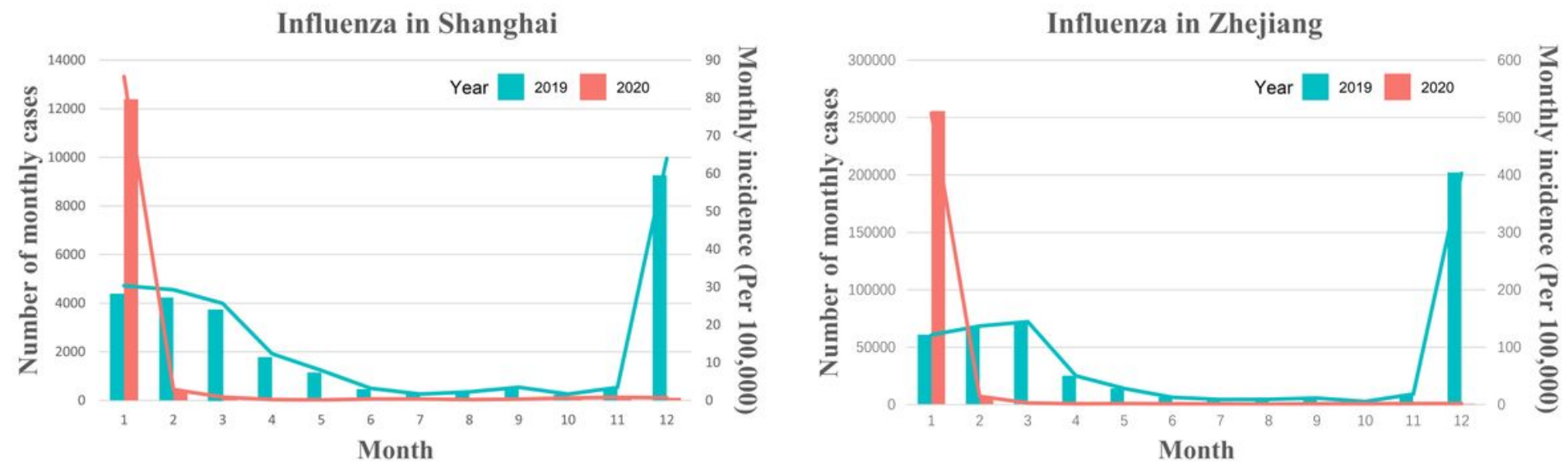

\section{Figure 3}

Differences in the monthly cases of influenza in Zhejiang and Shanghai between the 2017-2019 period and 2020 Notes: The horizontal and vertical axes reflect the onset months and number of monthly cases of influenza, respectively 

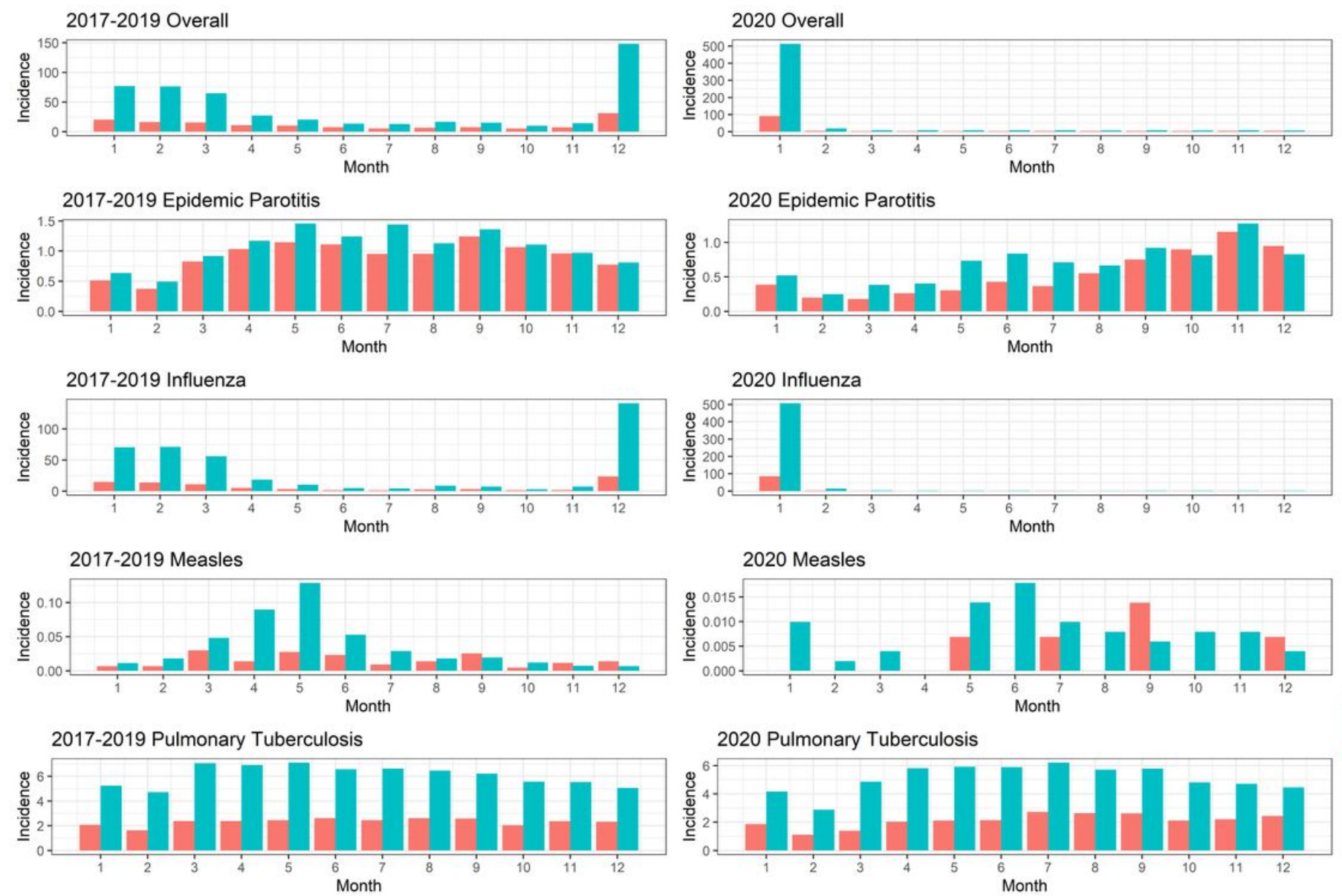

Variable Shanghai Zhejiang

2017-2019 Rubella
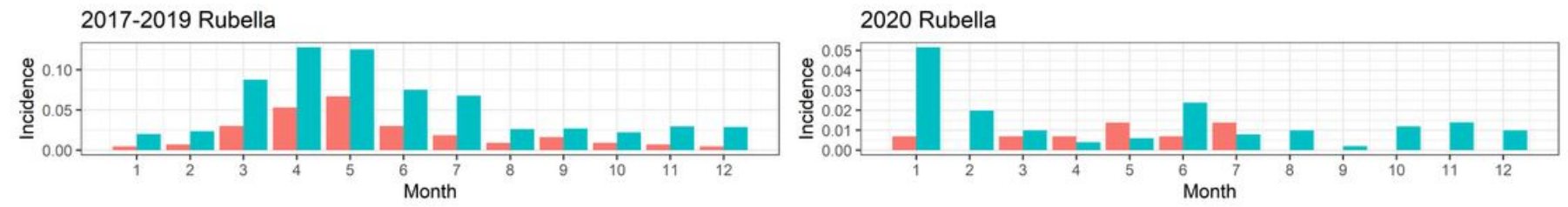

2017-2019 Scarlet Fever
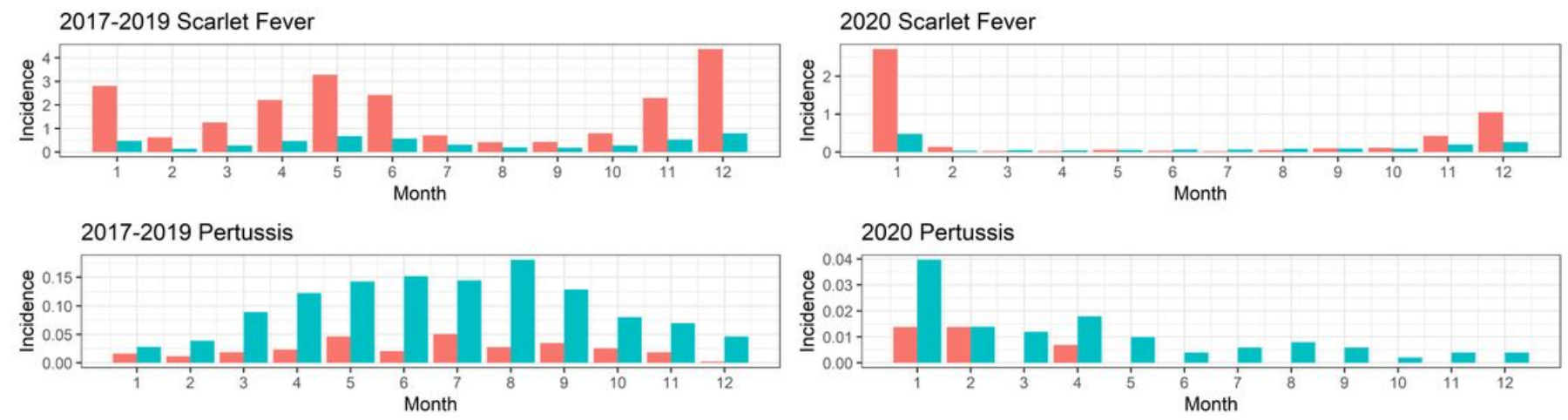

Figure 4

Differences in the monthly average incidence of eight respiratory infectious diseases in Shanghai and Zhejiang between the 2017-2019 period and 2020 Notes: The horizontal and vertical axes reflect the onset months and average monthly incidence of RID (per 100,000), respectively. 


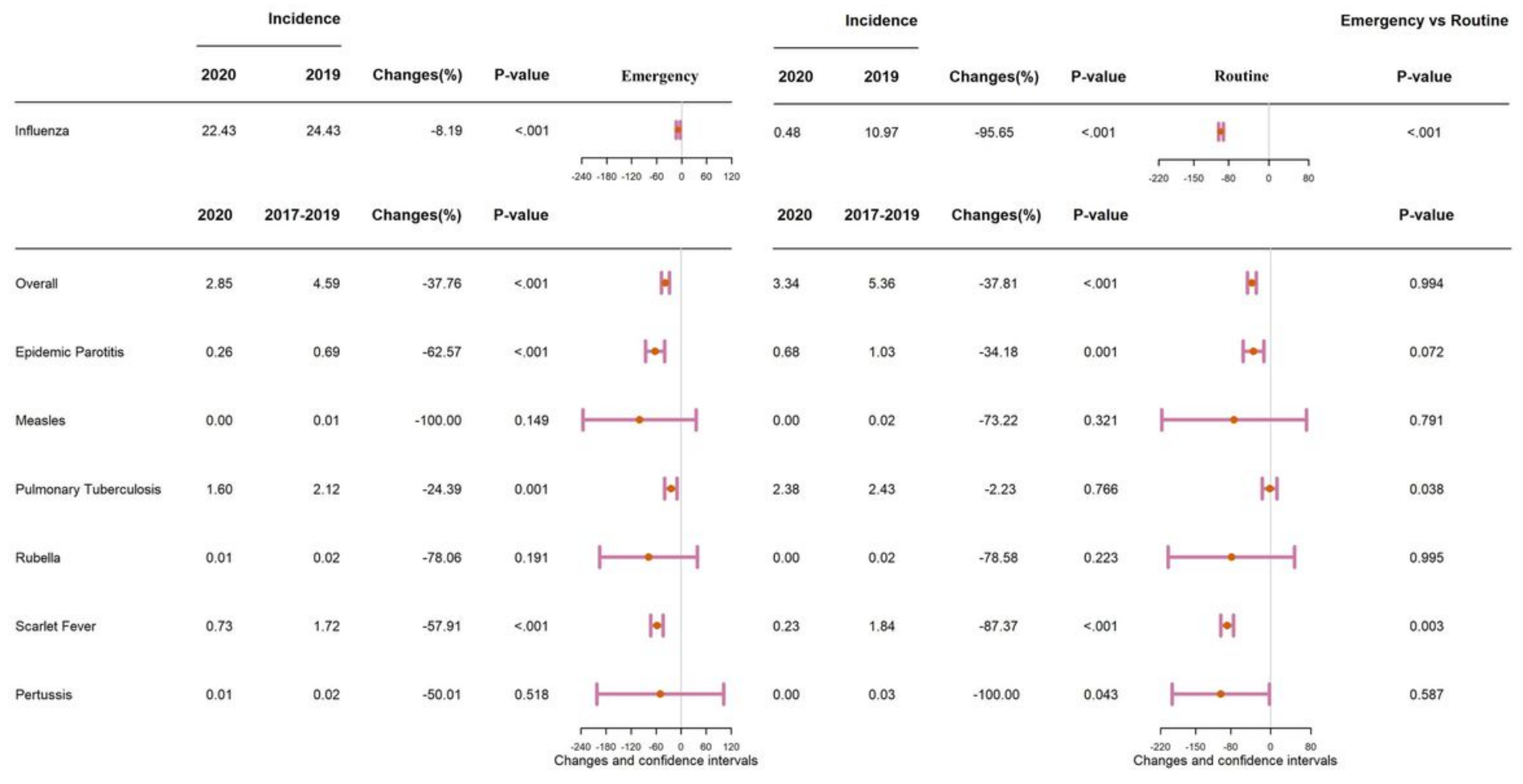

\section{Figure 5}

Differences in the average monthly incidence of eight respiratory infectious diseases in the emergency response stage (January to April 2020) and the routine response stage (May to December 2020) in Shanghai, China Notes: The pink lines reflect differences in $95 \%$ confidence interval values. The pink dot indicates the $50 \%$ median point. Changes $=(x 2-x 1) / x 1 \times 100 \%, x 1$ : average monthly incidence in 20172019, x2: average monthly incidence in 2020 . The p-values were computed using two proportional tests. For the emergency or routine response stages, the $\mathrm{p}$-values for the emergency versus the routine response stages were computed using two ratio tests. 


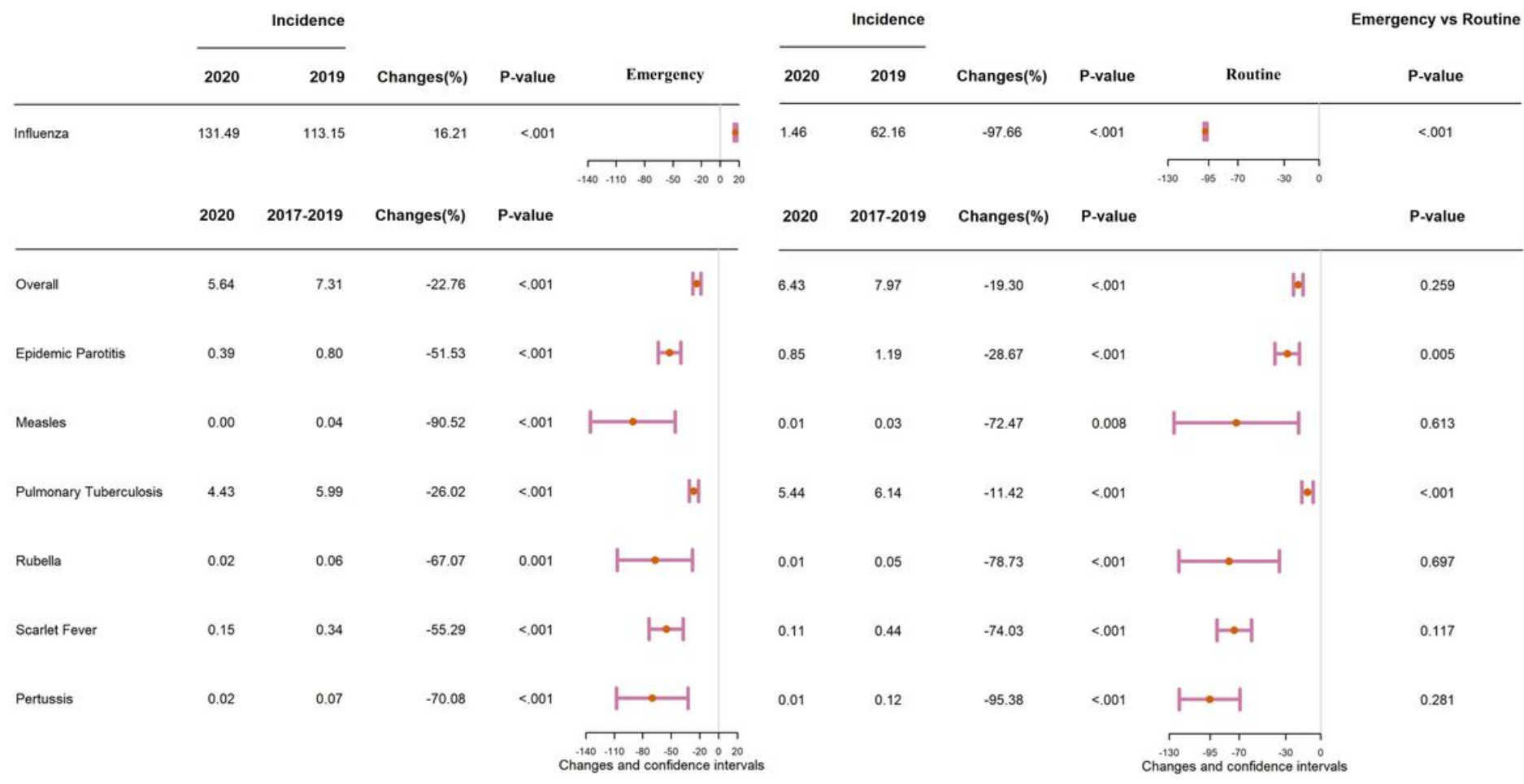

\section{Figure 6}

Differences in the average monthly incidence of eight respiratory infectious diseases in the emergency response stage (January to April 2020) and the routine response stage (May to December 2020) in Zhejiang Province, China Notes: The pink lines reflect differences in $95 \%$ confidence interval values. The pink dot indicates the $50 \%$ median point. Changes $=(x 2-x 1) / x 1 \times 100 \%, x 1$ : average monthly incidence in 2017-2019, x2: average monthly incidence in 2020. The $p$-values were computed using two proportional tests. For the emergency or routine response stages, the $p$-values for the emergency versus the routine response stages were computed using two ratio tests. 


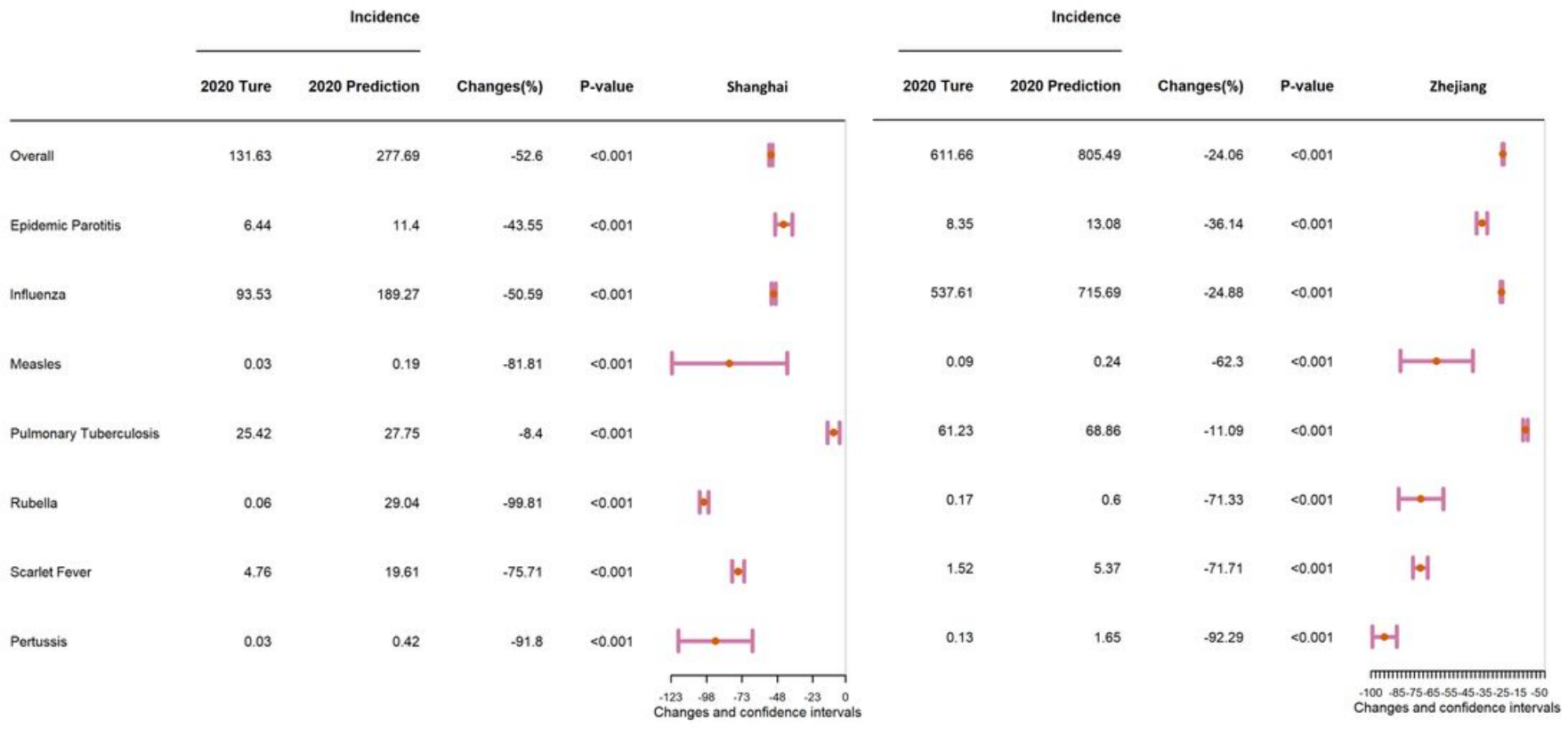

\section{Figure 7}

A comparison of the true and predicted average annual incidence of eight respiratory infectious diseases in Shanghai and Zhejiang of China in 2020 Notes: The pink lines reflect differences in 95\% confidence interval values. The pink dot indicates the $50 \%$ median point. The $p$-values were computed through two proportional tests . Changes $=(x 2-x 1) / x 1 \times 100 \%, x 1$ : average yearly incidence in 2020 prediction; $x 2$ : average yearly incidence in 2020 . 

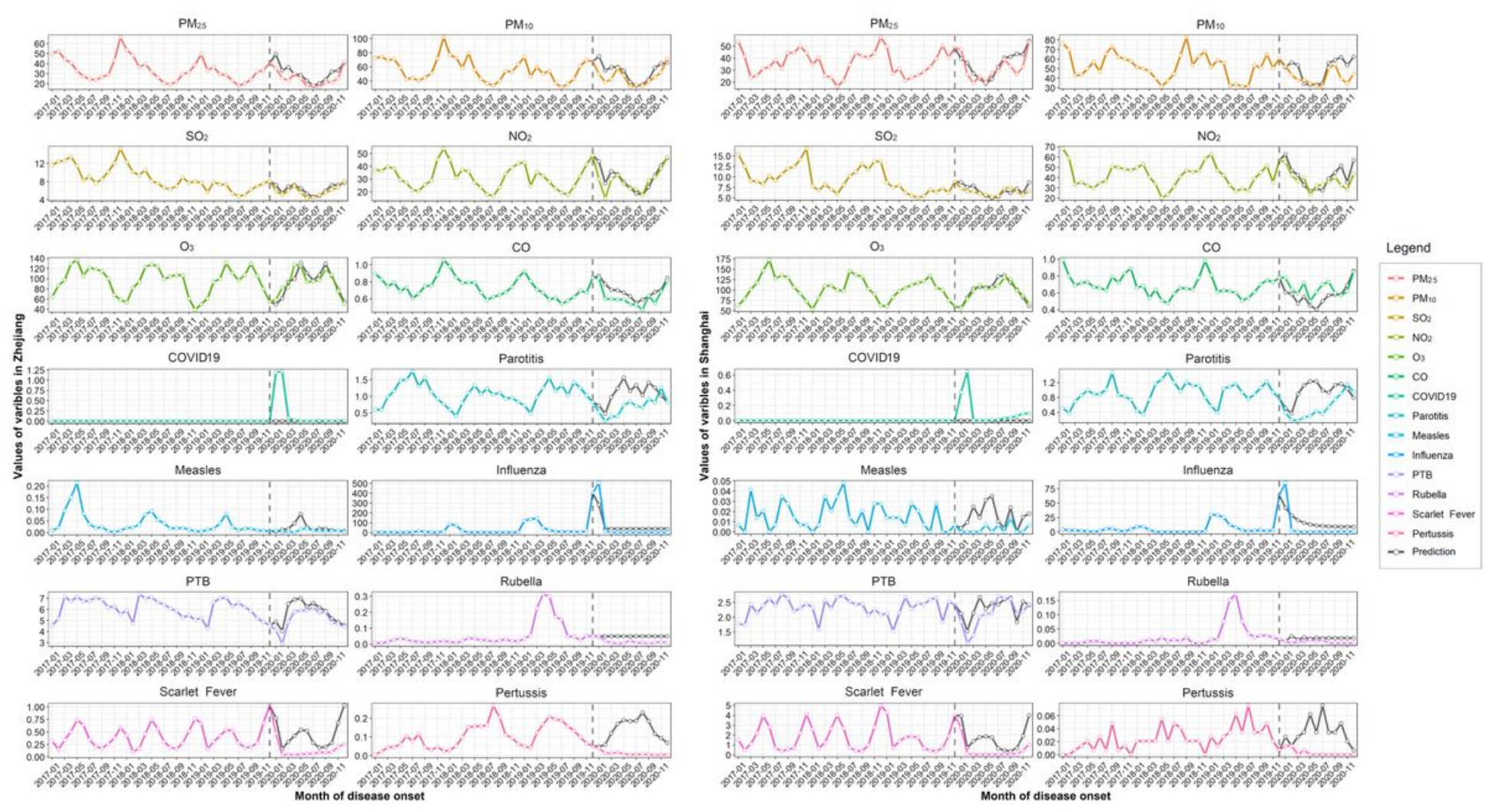

Figure 8

The actual monthly values of six air pollutants and eight respiratory infectious diseases in Zhejiang and Shanghai from 2017-2020 and hypothetical values for 2020 in the absence of coronavirus disease 2019 Notes: The horizontal axis depicts the months. The concentration of pollutants [SO2 ( $\mu \mathrm{g} / \mathrm{m} 3), \mathrm{NO} 2$ ( $\mu \mathrm{g} / \mathrm{m} 3)$ CO $(\mathrm{mg} / \mathrm{m} 3), 03(\mu \mathrm{g} / \mathrm{m} 3), \mathrm{PM} 2.5(\mu \mathrm{g} / \mathrm{m} 3), \mathrm{PM} 10(\mu \mathrm{g} / \mathrm{m} 3$ ] are plotted on the first six sub graphs on the vertical axis, and incidence (per 100,000) is depicted in the last eight subgraphs on the vertical axis. The black line in the figure represents the assumed values of various diseases and pollutants, and the coloured line represents the real values. 

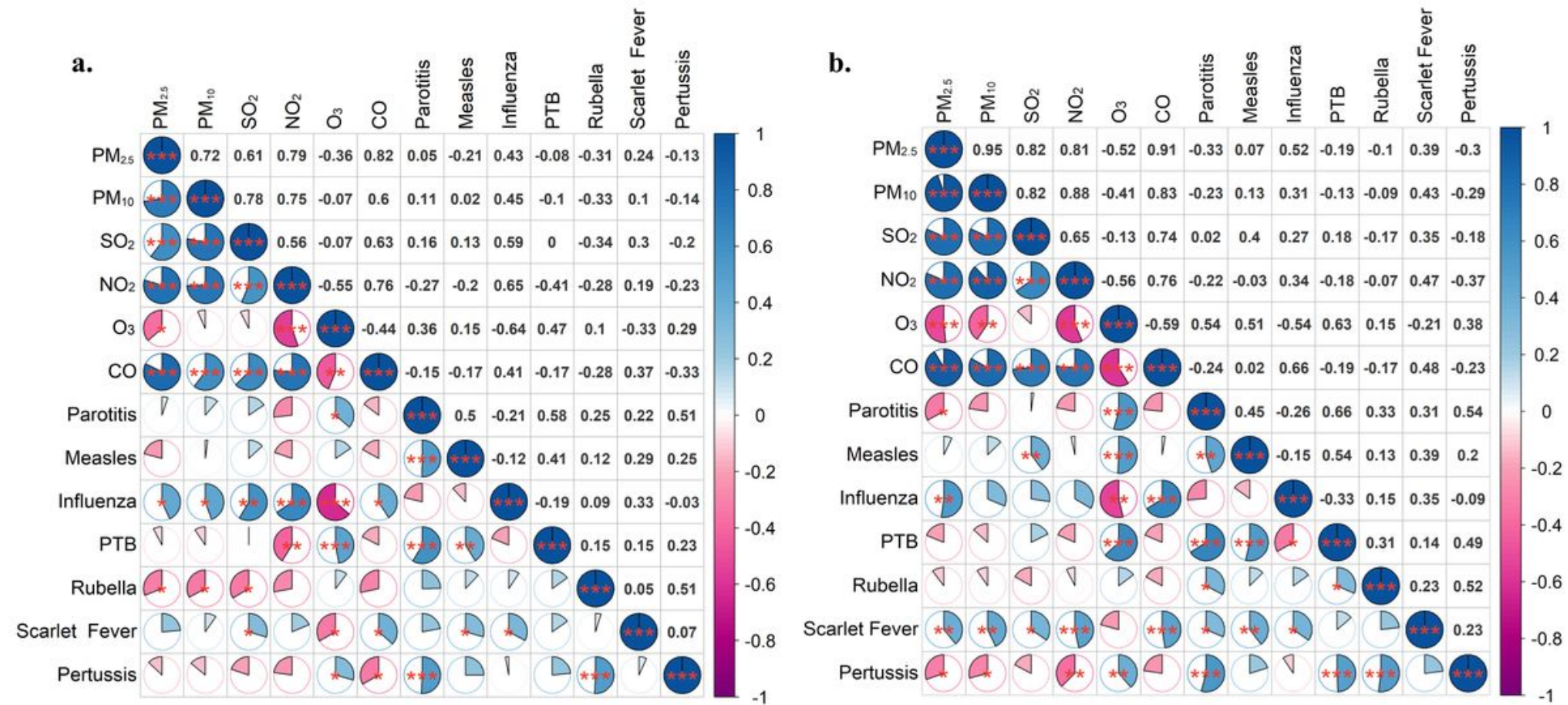

\section{Figure 9}

Pearson's correlation coefficients for air pollution concentrations and the incidence of seven respiratory infectious disease in Shanghai and Zhejiang Province, China, for the period 2017-2020 Notes: Showing PM2.5 particulate matter with an aerodynamic diameter of $<2.5 \mu \mathrm{m}$ and PM10 particulate matter with an aerodynamic diameter of < $10 \mu \mathrm{m}, \mathrm{SO}$ : sulphur dioxide, NO2: nitrogen dioxide, O3: ozone, CO: carbon monoxide .*: p-value $0.050 \geq p$-value of $>0.010 ; * \star$ : $p$-value of $0.01 \geq p$-value of $>0.001 ; * *$ : $p$-value of $\leq$ 0.001 PTB: Pulmonary tuberculosis. On the left figure notes the data from Shanghai; On the right figure notes the data from Zhejiang Province. 
a.
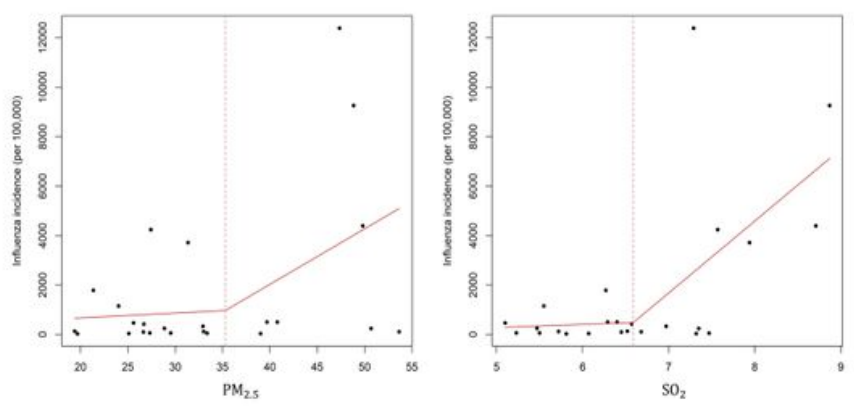

c.

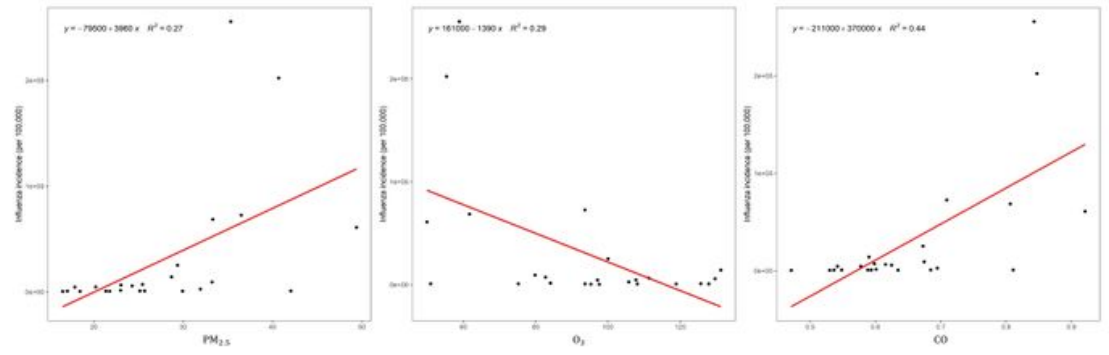

b.

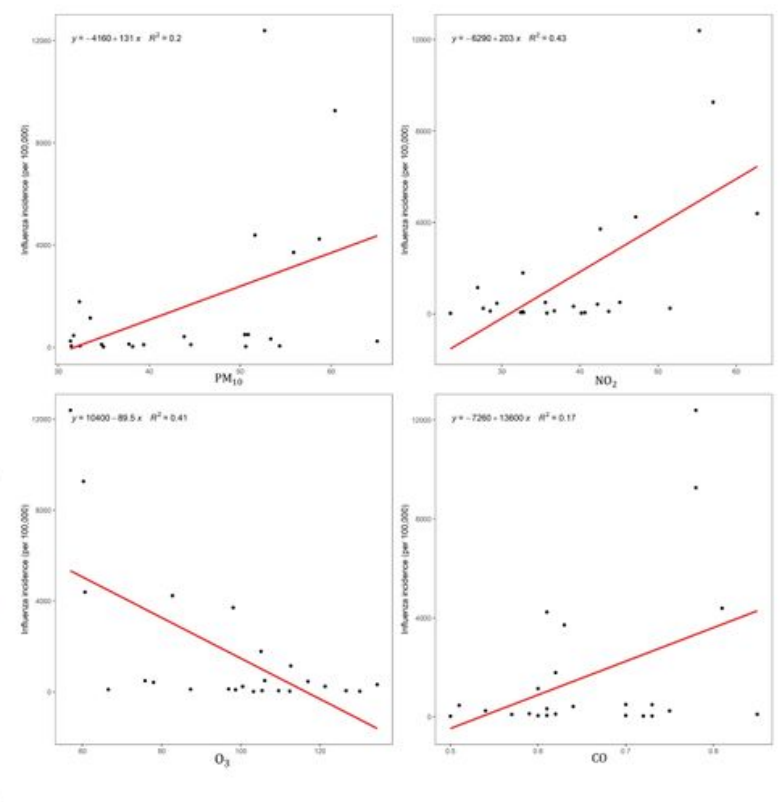

\section{Figure 10}

Linear regression of air pollution concentrations on influenza incidence in Shanghai and Zhejiang Province of China Notes: 10a: The effect of SO2 and PM2.5 concentrations on influenza incidence in Shanghai using piecewise linear regression; 10b: The effect of PM10, NO2, 03 and CO concentrations on influenza incidence in Shanghai using linear regression; 10c. The effect of PM2.5, 03 and CO concentrations on influenza incidence in Zhejiang Province using linear regression

\section{Supplementary Files}

This is a list of supplementary files associated with this preprint. Click to download.

- SupplementaryfilesFinalversion2021511.docx 